\title{
Reoperation for Recurrent
} Adrenocortical Carcinoma: A Systematic Review and Pooled Analysis of Population-Based Studies

\author{
Fan Zhang ${ }^{\dagger}$, Zhihong Liu ${ }^{\dagger}$, Dechao Feng ${ }^{\dagger}$, Yongquan Tang, Shenzhuo Liu, Kan Wu, \\ Fuxun Zhang, Yuchun Zhu* and Yiping Lu*
}

Department of Urology/Institute of Urology, West China Hospital, Sichuan University, Chengdu, China

\section{OPEN ACCESS}

Edited by:

Masha Livhits,

University of California, Los Angeles,

United States

Roberto Iglesias Lopes,

Hospital for Sick Children, Canada

Reviewed by:

Marco Massani,

ULSS2 Marca Trevigiana, Italy

*Correspondence:

Yiping Lu

luyiping_wch@126.com

Yuchun Zhu

zhuyuchun31@163.com

†These authors have contributed equally to this work and share first authorship

Specialty section:

This article was submitted to Surgical Oncology,

a section of the journal

Frontiers in Surgery

Received: 22 September 2021

Accepted: 17 January 2022

Published: 17 February 2022

Citation:

Zhang F, Liu Z, Feng D, Tang Y, Liu S, Wu K, Zhang F, Zhu Y and Lu Y (2022)

Reoperation for Recurrent

Adrenocortical Carcinoma: A

Systematic Review and Pooled Analysis of Population-Based Studies.

Front. Surg. 9:781406.

doi: 10.3389/fsurg.2022.781406
Background: Adrenocortical carcinoma (ACC) is a rare neoplasm with a high recurrence rate. This study aimed to assess the role of surgery in the clinical management of recurrent ACC.

Methods: The PubMed, Embase, Web of Science, and Cochrane Library databases were searched, and the hazard ratios were pooled.

Results: Patients who underwent resection for recurrence had significantly better OS or OS after recurrence than those who received only nonsurgical treatments (HR 0.34, $p<0.001)$. Prognostic factors were associated with decreased OS after recurrence, including multiple recurrence (HR 3.23, $p=0.001)$, shorter disease-free interval (HR 2.94, $p<0.001)$, stage III-IV of the original tumor (HR 6.17, $p=0.001)$, sex of male (HR 1.35, $p=0.04$ ), and initial non-R0 resection (HR 2.13, $p=0.001$ ). Prolonged OS after recurrence was observed in those who experienced incomplete resection ( $\mathrm{HR} 0.43,95 \% \mathrm{Cl} 0.31-0.52, \mathrm{I}^{2}=53 \%$ ) compared with patients who only received nonsurgical treatments. In the reoperated group, patients who underwent complete resection of recurrence had a prolonged OS after recurrence compared with those who underwent incomplete resection (HR 0.23, $p=0.004$ ).

Conclusions: We confirmed the role of reoperation in the clinical management of recurrent ACC. Select patients might benefit from debulking surgery. The preoperative evaluation of the complete resection of the recurrence is the key means to decide whether patients should undergo surgery. Other prognostic factors associated with prolonged OS include single recurrence site, relatively longer disease-free interval, stage $\mathrm{I}-\mathrm{Il}$ of the original tumor, and female sex.

Keywords: adrenocortical carcinoma, reoperation, recurrence, meta-analysis, system review

\section{INTRODUCTION}

Adrenocortical carcinoma (ACC) is a rare endocrine neoplasm with an estimated annual incidence of 1-2 per million inhabitants and has one of the poorest prognoses $(1,2)$. Patients are frequently asymptomatic, and most tumors are discovered at an advanced stage by symptoms of mass effects (3). Patients are usually diagnosed with an invasion of adjacent organs or metastatic disease, and the prognosis of ACC is extremely poor. 
For patients with stage I-II of the disease, the 5-year survival rate is $\sim 60 \%$ (4), whereas it is 40 and $28 \%$ for patients with stage III and IV disease, respectively (5).

However, evidence shows that patients with ACC rarely benefit from chemotherapy and radiation therapy. Complete tumor resection remains the only curative treatment for ACC. Although complete tumor resection has been performed, as many as $74 \%$ of patients experience local recurrence or distant metastasis (6). In recent decades, progress has been made in the clinical management of ACC patients using mitotane. However, for managing patients who undergo recurrent ACC, therapeutic options are still strictly limited. Prognostic factors of recurrent ACC have not yet been firmly established. Some recent studies suggested a benefit with survival in recurrent ACC patients undergoing reoperation $(7,8)$. However, whether we should take the very aggressive resection approach for patients with advanced disease is still controversial. The value of surgical treatment, especially when it requires repeated or debulking surgeries, remains to be confirmed. Therefore, we systematically pooled previous studies to assess the role of reoperation in the clinical management of recurrent ACC and attempted to identify the clinical characteristics of patients who can benefit from reoperation.

\section{METHODS}

\section{Data Source}

A systematic review was carried out following the Preferred Reporting Items for Systematic Reviews and Meta-Analyses (PRISMA) statement (9). The PubMed, Embase, Web of Science, and Cochrane Library databases were comprehensively searched between January 1990 and December 2020. The OVID tool was used to retrieve the Embase and Cochrane libraries. The following mesh terms were used: "adrenocortical carcinoma," "surgery," and "recurrence". In addition, we manually retrieved the related studies from the reference of retrieved studies in case of missing data.

\section{Inclusion and Exclusion Criteria}

Studies were considered eligible for final analysis if they: (1) were a population-based study; (2) involved patients with recurrent ACC; (3) compared reoperation with nonsurgical therapy, or identified the clinical characteristics of patients who can benefit more from reoperation; (4) used survival analysis to report relevant clinical outcomes; and (5) included sufficient data for analyses. Studies were excluded if they: (1) were in a non-English language; (2) did not distinguish recurrent ACC patients from metastatic ACC patients; (3) did not distinguish recurrent ACC patients from patients without recurrence (Studies were excluded from this research when they did not distinguish patients who did not undergo primary resection before metastasectomy from patients who underwent reoperation after the resection of primary tumor); (4) were not available or were published before 1990; (5) contained insufficient data for analyses; and (6) were review, cases, or conference abstracts. The titles and abstracts of all retrieved studies were screened by two independent investigators (ZF and FDC) to exclude irrelevant studies. Independent assessment was then conducted in duplicate for the full texts of potentially relevant studies. Any differences and conflicts were resolved through discussion and consensus by the group. For records containing the same population, the data of the latest study were extracted.

\section{Data Extraction and Quality Assessment}

The following relevant information was extracted from each eligible study: (1) publication details, first author's name, publication year, enrollment data and location; (2) age, number, and follow-up time of patients, clinical outcomes; and (3) hazard ratios (HRs), 95\% confidence intervals (CIs) of reoperation and other clinical parameters mentioned below for overall survival (OS). If only Kaplan-Meier curves were available, then we used Engauge Digitizer version 12.1 (http://digitizer. sourceforge.net/) to extract data, and HRs and 95\% CIs were then calculated using the described method (10-12). For studies containing both univariate and multivariate analyses, we prioritized the multivariate analysis results with the promise of eliminating the influence of other confounding factors. The Newcastle-Ottawa Quality Assessment Scale (NOS) was used (13) to evaluate the quality of retrospective studies, including three parameters: the selection parameter, the comparability parameter, and the outcome parameter. Studies with a score $>6$ were regarded as high quality. Stage classification was based on the European Network for the Study of Adrenal Tumors (ENSAT) or the American Joint Committee on Cancer (AJCC) $(14,15)$.

\section{Statistical Analysis}

We used HRs with 95\% CIs to assess the correlation between clinical parameters and outcomes of recurrent ACC patients. Further analysis was applied in patients who underwent reoperation to evaluate which patients would benefit more from reoperation. RevMan 5.3 software was used to calculate a summary hazard ratio or to indicate the association between clinical parameters and mortality. We used Cochran's Q test and Higgins I squared (I2) statistic to examine the heterogeneity between the studies. $P>0.1$ or $\mathrm{I} 2<50 \%$ was identified as no or moderate heterogeneity, and the fixed-effect model was applied; otherwise, the random-effects model was used (16). In addition, sensitivity analysis was conducted to identify the stability of the results. We also evaluated publication bias among the included studies based on Begg's test. $P<0.05$ was regarded as statistically significant.

\section{RESULTS}

\section{Identification and Selection of Included Studies}

A total of 697 studies were retrieved based on the described criteria. After removing 152 duplicate records, 545 articles were collected for preliminary screening of titles and abstracts. Then, we initially identified 49 potentially relevant papers and screened the full text. Ultimately, after excluding 37 studies [19 that only involved data on nonrecurrent ACC, 10 that did not have available data for analysis, five that contained patients 
who underwent metastasectomy without recurrence (17-21), and three that included the same population (21-23)], 11 retrospective studies including 964 patients from five countries were involved (Figure 1) $(7,8,15,24-31)$. Nine studies divided patients into reoperated and nonreoperated groups, while five studies reported the results of reoperated patients to identify prognostic factors that were related to improved OS for repeated surgeries (Table 1). Of the included studies, reoperation was performed in 573 patients, whereas 391 received only nonsurgical treatments after recurrence.
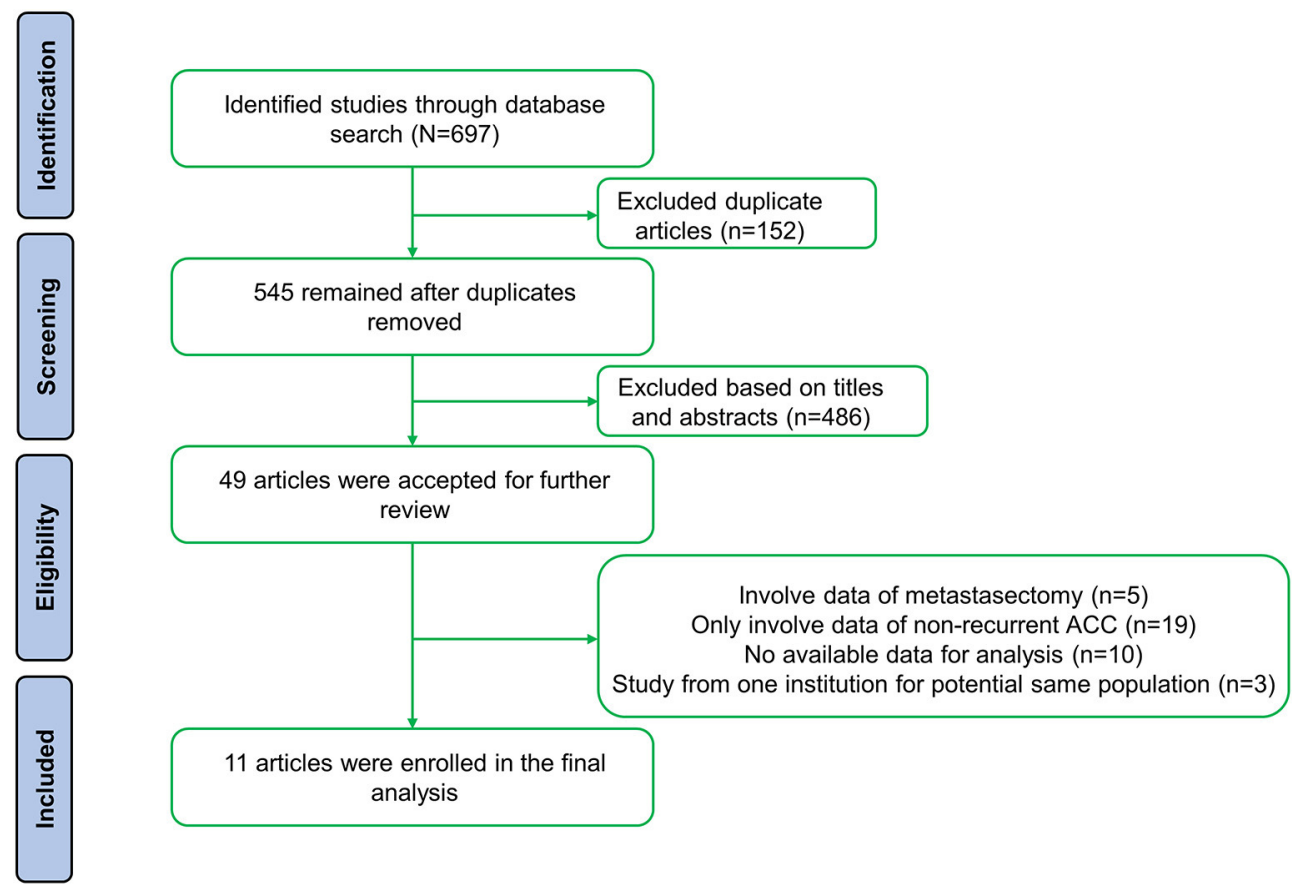

FIGURE 1 | Flow chart of the study search and selection.

TABLE 1 | Clinical characteristics of the included studies.

\begin{tabular}{|c|c|c|c|c|c|c|c|}
\hline References & $\begin{array}{l}\text { Enrollment date, } \\
\text { location }\end{array}$ & Study type & Treatment & $\begin{array}{l}\text { No. of patients } \\
\text { (reoperated vs. } \\
\text { nontreated) }\end{array}$ & $\begin{array}{l}\text { Follow-up, } \\
\text { months }\end{array}$ & Nos & $\begin{array}{l}\text { OS } \\
\text { calculation }\end{array}$ \\
\hline Erdogan et al. (29) & $\begin{array}{l}\text { Since 2003, } \\
\text { Germany }\end{array}$ & Retrospective & Reoperation vs. no surgery & 154 (101 vs. 53) & $\begin{array}{l}\text { Median } 69 \text { (range } \\
\text { 30-297) }\end{array}$ & 7 & $\begin{array}{l}\text { After } \\
\text { recurrence }\end{array}$ \\
\hline Dy et al. (28) & 1980-2010, USA & Retrospective & Reoperation vs. no surgery & 93 (67 vs. 26) & $\begin{array}{l}\text { Median } 48 \text { (range } \\
2-239 \text { ) }\end{array}$ & 7 & $\begin{array}{l}\text { After } \\
\text { recurrence }\end{array}$ \\
\hline Bellantone et al. (25) & Not reported, Italy & Retrospective & Reoperation vs. no surgery & 52 (20 vs. 32) & Median 21.7 & 7 & Overall \\
\hline Tran et al. (15) & 1997-2014. USA & Retrospective & Reoperation & 56 & Not reported & 8 & $\begin{array}{l}\text { After } \\
\text { reoperation }\end{array}$ \\
\hline Schulick et al. (26) & Not reported, USA & Retrospective & Reoperation & 47 & Median 28 & 7 & $\begin{array}{l}\text { After } \\
\text { reoperation }\end{array}$ \\
\hline Zhang et al. (31) & 2009-2020, China & Retrospective & Reoperation vs. no surgery & 47 (21 vs. 26) & Median 25 & 8 & $\begin{array}{l}\text { After } \\
\text { recurrence }\end{array}$ \\
\hline Pommier et al. (30) & 1980-1991, USA & Retrospective & Reoperation vs. no surgery & 45 (26 vs. 19) & Median 28 & 7 & Overall \\
\hline
\end{tabular}




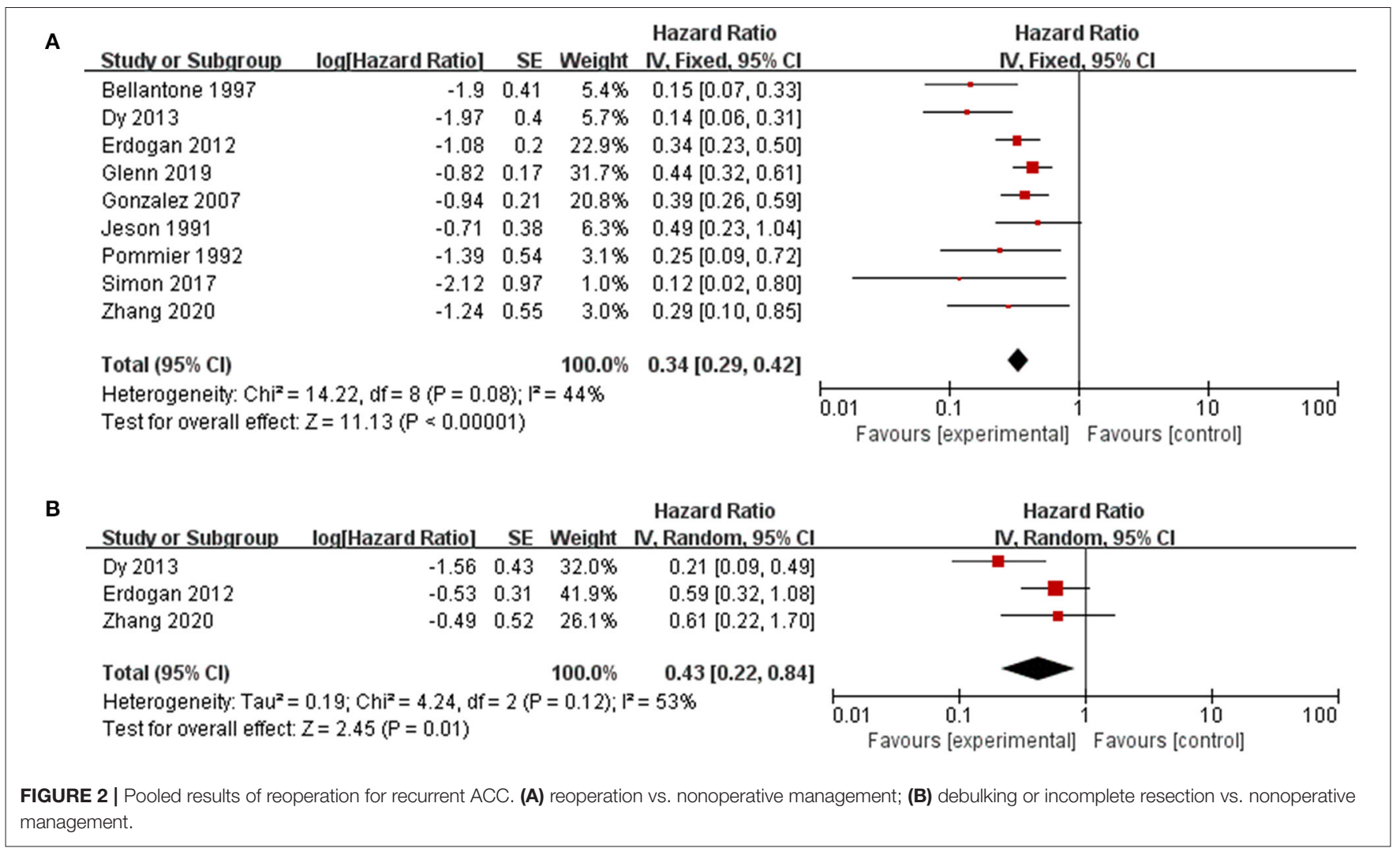

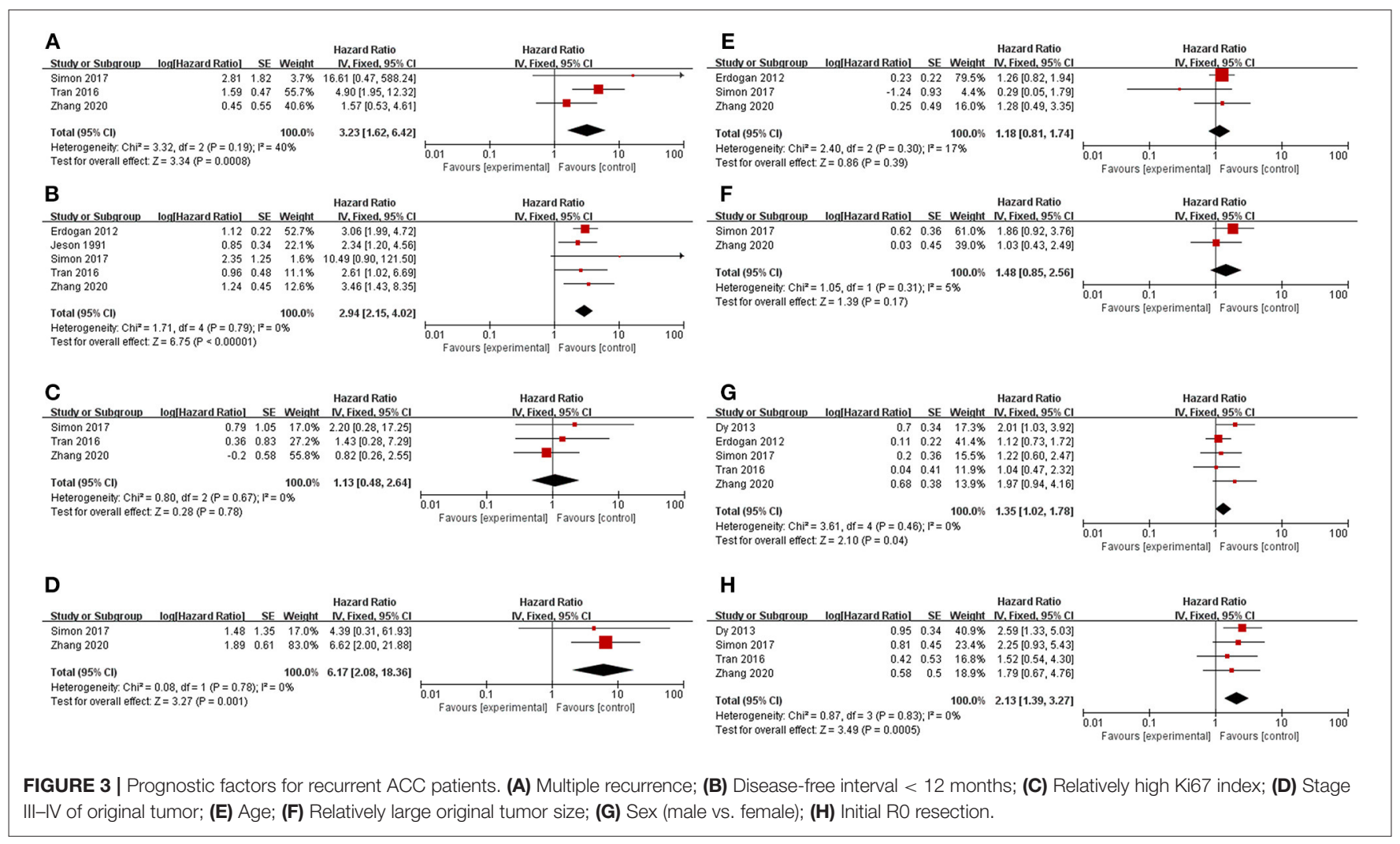




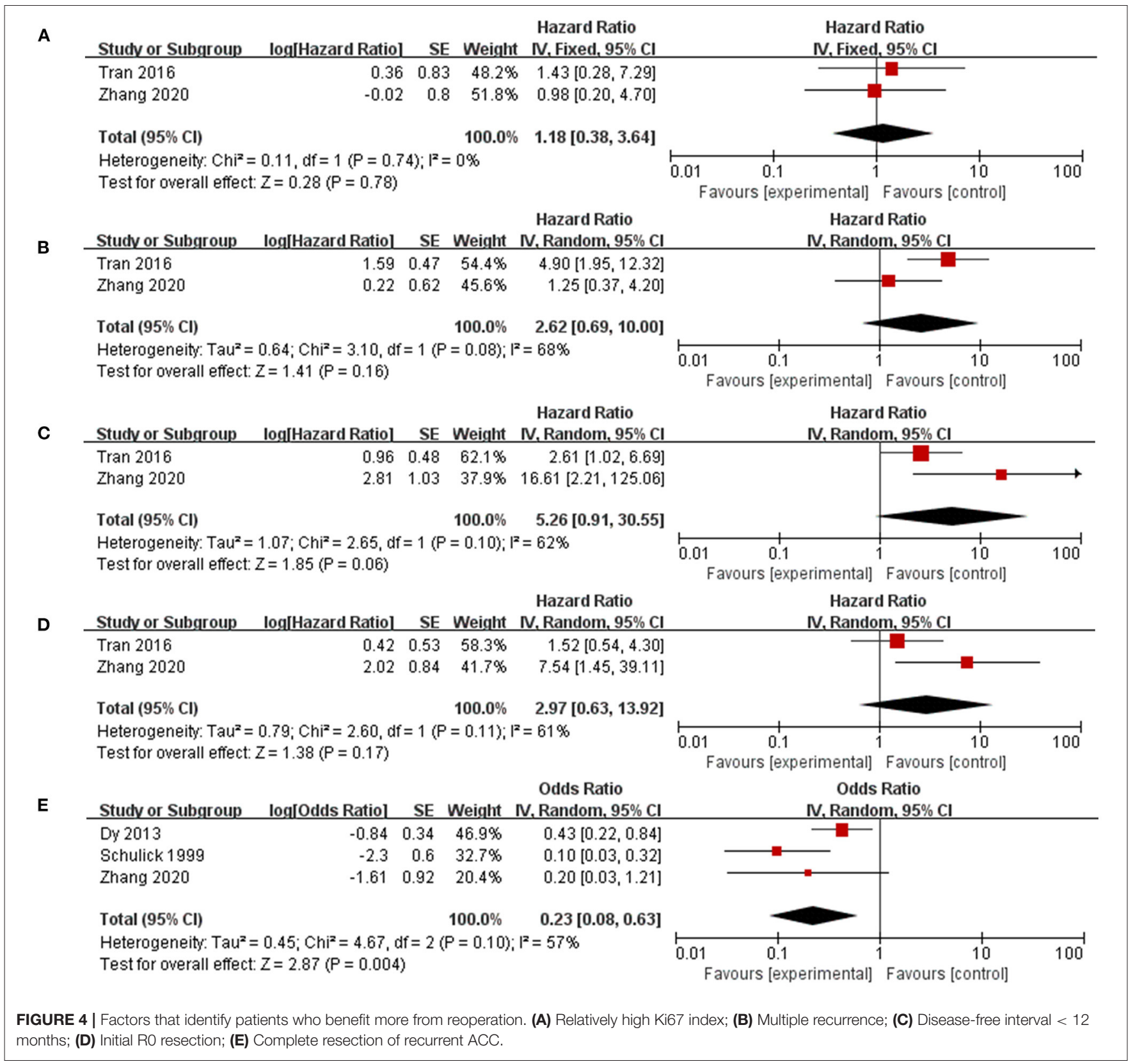

\section{Prognostic Factors for Recurrent ACC}

Patients who underwent resection for recurrence had significantly better OS or OS after recurrence than those who received only nonsurgical treatments (HR 0.34, 95\% CI $0.29-0.42, \mathrm{I}^{2}=44 \%$, Figure 2). Factors were identified as prognostic factors associated with decreased OS after recurrence (Figure 3), including multiple recurrence (HR 3.23, 95\% CI $1.62-6.42, \mathrm{I}^{2}=40 \%$ ), shorter DFI (HR 2.94, 95\% CI 2.15-4.02, $\mathrm{I}^{2}=0$ ), stage III-IV of original tumor (HR 6.17 , 95\% CI $\left.2.08-18.36, \mathrm{I}^{2}=0\right)$, sex (HR 1.35, 95\% CI 1.02-1.78, $\mathrm{I}^{2}=0$ ), and initial non-R0 resection (HR 2.13, 95\% CI 1.39-3.27, $\mathrm{I}^{2}$ $=0$ ). However, Ki67 (HR 1.13, 95\% CI 0.48-2.64, $\mathrm{I}^{2}=0$ ), age (HR 1.18, 95\% CI 0.81-1.74, $\left.\mathrm{I}^{2}=17 \%\right)$, original tumor size ( $\mathrm{HR}$
$1.48,95 \%$ CI $0.85-2.56, \mathrm{I}^{2}=5 \%$ ), and adjuvant therapy (HR $0.92,95 \%$ CI $0.57-1.49, \mathrm{I}^{2}=0$ ) were not significantly related to OS after recurrence. In addition, three studies evaluated the effect of debulking or incomplete resection of recurrent ACC (Figure 2), and compared with patients receiving only nonsurgical treatments, a prolonged OS after recurrence was observed in those who experienced incomplete resection (HR $0.43,95 \%$ CI $\left.0.31-0.52, \mathrm{I}^{2}=53 \%\right)$.

\section{Identify Patients Who Benefit More From Reoperation}

Patients with repeated surgeries were grouped by different parameters in five studies to identify potential prognostic 
factors related to a better prognosis (Figure 4). Patients with multiple recurrence (HR 0.2.62, 95\% CI 0.69-10.00, $\mathrm{I}^{2}=68 \%$ ), shorter DFI (HR 5.26, 95\% CI 0.91-30.55, $\mathrm{I}^{2}=62 \%$ ), and noninitial R0 resection (HR 2.97, 95\% CI 0.63-13.92, $\mathrm{I}^{2}=61 \%$ ) tended to benefit less from reoperation, but the results were not significantly different. Furthermore, those who experienced complete resection of recurrent tumors (HR 0.23, 95\% CI $0.08-$ $0.63, \mathrm{I}^{2}=0$ ) were associated with a significantly better OS after recurrence.

\section{Subgroup Analysis}

Subgroup analyses were conducted based on the region (America, Europe), OS definition (OS after recurrence, OS calculated from the first diagnosis), and the number of patients $(<60$ and $\geq 60$ ). In all subgroups, patients who underwent reoperation after recurrence were observed to have better OS or OS after recurrence, with all $p \leq 0.001$ (Table 2 ).

\section{Sensitivity Analysis and Publication Bias}

Due to the small number of included studies, we only performed sensitivity analysis and publication bias for reoperation. The sensitivity analysis is presented in Figure 5, and no evidence of publication bias was observed based on Begg's test $(p=0.180)$.

\section{DISCUSSION}

Adrenocortical carcinoma (ACC) is an aggressive tumor with a high recurrence rate. The current effective treatments for recurrent ACC are still limited. ACC is relatively resistant to chemotherapy and radiotherapy. Mitotane is the only effective drug approved by the FDA that has a temporary antitumor effect on ACC. However, this drug is limited by a very moderate response rate, a narrow therapeutic window, and a non-eligible rate of patients experiencing significant side effects $(32,33)$. The limitations of chemotherapy and radiotherapy for recurrent ACC patients highlight the importance of reoperation, which is regarded as a very aggressive approach but as the only curative treatment.

TABLE 2 | Subgroup analysis of reoperation for recurrent ACC based on region, definition of overall survival and number of included patients.

\begin{tabular}{lcllll}
\hline Variable & $\begin{array}{c}\text { No. of } \\
\text { studies }\end{array}$ & Model & HR (95\% Cl) & p value & $\mathbf{I}^{\mathbf{2}} \mathbf{( \% )}$ \\
\hline $\begin{array}{l}\text { Total } \\
\text { Region }\end{array}$ & 9 & Fixed & $0.34(0.29-0.42)$ & $<0.001$ & 44 \\
$\quad$ America & 5 & Random & $0.35(0.24-0.50)$ & $<0.001$ & 51 \\
$\quad$ Europe & 3 & Fixed & $0.28(0.20-0.40)$ & $<0.001$ & 50 \\
OS definition & & & & & \\
$\quad$ OS after recurrence & 6 & Fixed & $0.33(0.26-0.42)$ & $<0.001$ & 34 \\
$\quad$ OS & 3 & Random & $0.27(0.13-0.57)$ & 0.001 & 69 \\
No. of patients & & & & & \\
$\quad \geq 60$ & 4 & Random & $0.34(0.24-0.48)$ & $<0.001$ & 59 \\
$\quad<60$ & 5 & Fixed & $0.27(0.17-0.41)$ & $<0.001$ & 24
\end{tabular}

This study found that prolonged OS after recurrence was significantly related to reoperation in recurrent ACC patients, indicating that repeated surgeries are feasible for ACC recurrence. Furthermore, reoperation for ACC recurrence is also a relatively safe option in selected patients, and the mortality and morbidity in previous studies remained accepted. Simon et al. reported that thirty-day mortality was 3\% (7), while Tran et al. reported thirty-day mortality of $5.4 \%$, and serious complications were found in $18.6 \%$ of patients (15). We also evaluated the role of reoperation by subgroup analysis, and the OS and OS after recurrence were significantly different between the two groups irrespective of region or cohort number.

Despite the fact that repeat surgeries were associated with better OS after recurrence, we noticed an inevitable selection bias for the reoperation inclusion criteria. In three studies (7, $28,31)$ comparing the clinical and tumor characteristics of the two groups (reoperated vs. nonreoperated), those patients who underwent reoperation tended to have relatively smaller tumors, relatively shorter DFIs, a lower frequency of stage III-IV tumors, a single recurrence site, and a lower possibility of distant metastasis. This observation can be explained by tumors with these characteristics often being evaluated as an easy to complete resection during preoperative evaluation. Our study found that patients experiencing complete resection of recurrent lesions could benefit more from reoperation. Therefore, to select suitable patients for reoperation, it is extremely important to evaluate the possibility of complete resection of the lesion preoperatively. Apart from complete resection, there is a tendency that recurrent ACC patients with a single recurrence site, relatively longer DFI, and initial $\mathrm{R} 0$ resection would benefit more from reoperation. Consequently, we recommend that reoperation should be given priority in patients with these characteristics.

Interestingly, the pooled results showed that recurrent ACC patients benefited from prolonged survival even when they only received debulking or incomplete surgery. It is still controversial whether repeated surgeries should be performed in patients with advanced disease. Current guidelines do not recommend surgery for patients with multiple metastases. However, our study found that patients with advanced or multiple recurrent diseases might not be contraindicated for debulking or incomplete surgeries. Selected patients might benefit from a decrease in tumor volume, but this result could be restricted by the number of samples or some selection bias, and more cases should be accumulated and would be of great value.

In addition to reoperation, we identified several prognostic factors associated with OS after recurrence. The characteristics of tumors in primary resection are associated with survival when patients undergo recurrence. Initial R0 resection and tumor stage I-II are good prognostic signs that indicate that combat against recurrent ACC has already begun at the initial resection. A systematic meta-analysis conducted by $\mathrm{Hu}$ et al. reported that minimally invasive adrenalectomy surgery approaches were associated with earlier recurrence and more positive surgical margins and peritoneal recurrence than open adrenalectomy 


\begin{tabular}{|c|c|c|}
\hline Study & $\begin{array}{c}\text { Hazard Ratio } \\
\text { IV, Fixed, } 95 \% \mathrm{Cl}\end{array}$ & $\begin{array}{c}\text { Hazard Ratio } \\
\text { IV, Fixed, } 95 \% \mathrm{Cl}\end{array}$ \\
\hline Omitting Bellantone 1997 & $0.36[0.30 ; 0.44]$ & \\
\hline Omitting Dy 2013 & $0.36[0.30 ; 0.44]$ & \\
\hline Omitting Erdogan 2012 & $0.35[0.28 ; 0.43]$ & \\
\hline Omitting Glenn 2019 & $0.31[0.25 ; 0.39]$ & \\
\hline Omitting Gonzalez 2007 & $0.33[0.27 ; 0.41]$ & \\
\hline Omitting Jeson 1991 & $0.34[0.28 ; 0.41]$ & \\
\hline Omitting Pommier 1992 & $0.35[0.29 ; 0.42]$ & \\
\hline Omitting Simon 2017 & $0.35[0.29 ; 0.42]$ & \\
\hline Omitting Zhang 2020 & $0.35[0.29 ; 0.42]$ & \\
\hline \multirow[t]{2}{*}{ Total $(95 \% \mathrm{Cl})$} & $0.34[0.29 ; 0.42]$ & \\
\hline & & 0.5 \\
\hline
\end{tabular}

FIGURE 5 | Sensitivity analysis of reoperation for recurrent ACC.

(5). Due to the fragility of ACC, it is essential for surgeons to carefully choose an appropriate surgical technique and achieve R0 resection of the primary tumor.

Another important prognostic factor for recurrent ACC patients is the length of time between initial resection and the first diagnosis of recurrence. A relatively shorter DFI, usually with a cutoff value of 12 months, is an independent prognostic feature predicting a poor prognosis. Winifred et al. showed that the DFI was significantly different between patients surviving $>24$ months after recurrence and patients surviving $<12$ months (34). In our opinion, DFI is an indicator of tumor characteristics and malignancy, which is similar to Ki67. The prognostic role of Ki67 in adrenocortical carcinoma after primary resection has already been reported by several studies $(35,36)$. However, in our study, no significant association was found between Ki67 and OS after recurrence. It might be partially explained that Ki67 could be used for stratifying patients with rapid recurrence, which causes a high rate of death risk and relatively shorter OS. Once the tumor recurs, this indicator is no longer significantly related to OS.

Another remarkable finding was that OS after recurrence was influenced by sex. Male patients had a worse prognosis after tumor recurrence. To the best of our knowledge, the association between sex and the prognosis of recurrent ACC has never been reported. This difference between sex and tumor mortality has been observed in many tumors; for example, men with breast cancer face high mortality rates (37). The exact mechanisms by which male patients might have a worse prognosis remain unknown and require further research.

Our research is not without obvious limitations. First, we only included 11 studies and 964 recurrent ACC patients, which is a

\section{REFERENCES}

1. Else T, Kim AC, Sabolch A, Raymond VM, Kandathil A, Caoili EM, et al. Adrenocortical carcinoma. Endocr Rev. (2014) 35:282-326. doi: 10.1210/er.2013-1029

2. Fassnacht M, Libé R, Kroiss M, Allolio B. Adrenocortical carcinoma: a clinician's update. Nat Rev Endocrinol. (2011) 7:323-35. doi: 10.1038/nrendo.2010.235 relatively small number and may limit the effectiveness of the results to some extent. Next, all studies were retrospective and had an inherent bias, which may have influenced our results and partially resulted in heterogeneity between studies. To minimize this bias, we performed sensitivity and subgroup analysis to further evaluate the stability of the included results. In addition, some factors may impact the results, including adjuvant therapy, follow-up time, different treatment protocols from different institutions, etc. We performed a prior selection of multivariate analysis results instead of univariate analysis to minimize the influence of other factors. Furthermore, the time range of patients included was extensive from 1965 to 2020, which may affect our results due to the development and variation of surgical techniques and medical treatments for recurrent ACC.

\section{CONCLUSIONS}

Our results confirm the role of reoperation in the clinical management of recurrent ACC. Select patients might benefit from debulking surgery. Preoperative evaluation of the complete resection of the recurrence is the key point to decide whether patients should undergo surgery. Furthermore, other prognostic factors associated with prolonged OS after recurrence include a single recurrence site, relatively longer DFI, stage I-II of the original tumor, and sex.

\section{DATA AVAILABILITY STATEMENT}

The original contributions presented in the study are included in the article/supplementary material, further inquiries can be directed to the corresponding authors.

\section{AUTHOR CONTRIBUTIONS}

FaZ, ZL, and DF wrote the main manuscript text. The data were collected by FaZ and DF and assessed by FaZ and ZL. Study was designed by YZ and YL. The figures and tables were prepared by FuZ, YT, and SL. All authors reviewed the manuscript, contributed to the article, and approved the submitted version.

\section{FUNDING}

This work was supported by 1.3.5 Project for Disciplines of Excellence-Clinical Research Incubation Project, West China Hospital, Sichuan University. 
carcinoma: a meta-analysis. Ann Surg Oncol. (2020) 27:385869. doi: 10.1245/s10434-020-08454-1

6. Freire DS, Siqueira SA, Zerbini MC, Wajchenberg BL, Corrêa-Giannella ML, Lucon AM, et al. Development and internal validation of an adrenal cortical carcinoma prognostic score for predicting the risk of metastasis and local recurrence. Clin Endocrinol (Oxf). (2013) 79:468-75. doi: 10.1111/cen.12174

7. Simon G, Pattou F, Mirallie E, Lifante JC, Nomine C, Arnault V, et al. Surgery for recurrent adrenocortical carcinoma: A multicenter retrospective study. Surgery. (2017) 161:249-55. doi: 10.1016/j.surg.2016.08.058

8. Glenn JA, Else T, Hughes DT, Cohen MS, Jolly S, Giordano TJ, et al. Longitudinal patterns of recurrence in patients with adrenocortical carcinoma. Surgery. (2019) 165:186-95. doi: 10.1016/j.surg.2018. 04.068

9. Moher D, Liberati A, Tetzlaff J, Altman DG. Preferred reporting items for systematic reviews and meta-analyses: the PRISMA statement. PLoS Med. (2009) 6:e1000097. doi: 10.1371/journal.pmed.1000097

10. Guyot P, Ades AE, Ouwens MJ, Welton NJ. Enhanced secondary analysis of survival data: reconstructing the data from published Kaplan-Meier survival curves. BMC Med Res Methodol. (2012) 12:9. doi: 10.1186/1471-2288-12-9

11. Liu FT, Xue QZ, Zhu PQ, Luo HL, Zhang Y, Hao T. Long noncoding RNA AFAP1-AS1, a potential novel biomarker to predict the clinical outcome of cancer patients: a meta-analysis. Onco Targets Ther. (2016) 9:424754. doi: 10.2147/OTT.S107188

12. Tierney JF, Stewart LA, Ghersi D, Burdett S, Sydes MR. Practical methods for incorporating summary time-to-event data into meta-analysis. Trials. (2007) 8:16. doi: $10.1186 / 1745-6215-8-16$

13. Stang A. Critical evaluation of the Newcastle-Ottawa scale for the assessment of the quality of nonrandomized studies in meta-analyses. Eur J Epidemiol. (2010) 25:603-5. doi: 10.1007/s10654-010-9491-z

14. Fassnacht M, Johanssen S, Quinkler M, Bucsky P, Willenberg HS, Beuschlein F, et al. Limited prognostic value of the 2004 International Union Against Cancer staging classification for adrenocortical carcinoma: proposal for a Revised TNM Classification. Cancer. (2009) 115:243-50. doi: 10.1002/cncr.24030

15. Tran TB, Maithel SK, Pawlik TM, Wang TS, Hatzaras I, Phay JE, et al. Clinical score predicting long-term survival after repeat resection for recurrent adrenocortical carcinoma. J Am Coll Surg. (2016) 223:794803. doi: 10.1016/j.jamcollsurg.2016.08.568

16. Higgins JP, Thompson SG, Deeks JJ, Altman DG. Measuring inconsistency in meta-analyses. BMJ. (2003) 327:557-60. doi: 10.1136/bmj.327.7414.557

17. den Winkel JO, Pfannschmidt J, Muley T, Grunewald C, Dienemann H, Fassnacht $\mathrm{M}$, et al. Metastatic adrenocortical carcinoma: results of 56 pulmonary metastasectomies in 24 patients. Annals of Thoracic Surgery. (2011) 92:1965-70. doi: 10.1016/j.athoracsur.2011.07.088

18. Kemp CD, Ripley RT, Mathur A, Steinberg SM, Nguyen DM, Fojo T, et al. Pulmonary resection for metastatic adrenocortical carcinoma: the National Cancer Institute experience. Ann Thorac Surg. (2011) 92:1195200. doi: 10.1016/j.athoracsur.2011.05.013

19. Datrice NM, Langan RC, Ripley RT, Kemp CD, Steinberg SM, Wood BJ, et al. Operative management for recurrent and metastatic adrenocortical carcinoma. J Surg Oncol. (2012) 105:709-13. doi: 10.1002/jso.23015

20. Ripley RT, Kem $p$ CD, Davis JL, Langan RC, Royal RE, Libutti SK, et al. Liver resection and ablation for metastatic adrenocortical carcinoma. Ann Surg Oncol. (2011) 18:1972-9. doi: 10.1245/s10434-011-1564-z

21. Dy BM, Strajina V, Cayo AK, Richards ML, Farley DR, Grant CS, et al. Surgical resection of synchronously metastatic adrenocortical cancer. Ann Surg Oncol. (2015) 22:146-51. doi: 10.1245/s10434-014-3944-7

22. Crucitti F, Bellantone R, Ferrante A, Boscherini M, Crucitti P, Carbone G, et al. The Italian registry for adrenal cortical carcinoma: Analysis of a multiinstitutional series of 129 patients. Surgery. (1996) 119:16170. doi: 10.1016/S0039-6060(96)80164-4

23. Baur J, Buntemeyer TO, Megerle F, Deutschbein T, Spitzweg C, Quinkler M, et al. Outcome after resection of Adrenocortical Carcinoma liver metastases: a retrospective study. BMC Cancer. (2017) 17. doi: 10.1186/s12885-017-3506-z

24. Jensen JC, Pass HI, Sindelar WF, Norton JA. Recurrent or metastatic disease in select patients with adrenocortical carcinoma.
Aggressive resection vs chemotherapy. Arch Surg. (1991) 126:45761. doi: 10.1001/archsurg.1991.01410280059008

25. Bellantone R, Ferrante A, Boscherini M, Lombardi CP, Crucitti P, Crucitti F, et al. Role of reoperation in recurrence of adrenal cortical carcinoma: results from 188 cases collected in the Italian National Registry for Adrenal Cortical Carcinoma. Surgery. (1997) 122:1212-8. doi: 10.1016/S0039-6060(97)90229-4

26. Schulick RD, Brennan MF. Long-term survival after complete resection and repeat resection in patients with adrenocortical carcinoma. Ann Surg Oncol. (1999) 6:719-26. doi: 10.1007/s10434-999-0719-7

27. Gonzalez RJ, Tamm EP, Ng C, Phan AT, Vassilopoulou-Sellin $\mathrm{R}$, Perrier ND, et al. Response to mitotane predicts outcome in patients with recurrent adrenal cortical carcinoma. Surgery. (2007) 142:867-75. doi: 10.1016/j.surg.2007.09.006

28. Dy BM, Wise KB, Richards ML, Young WE, Grant CS, Bible KC, et al. Operative intervention for recurrent adrenocortical cancer. Surgery. (2013) 154:1292-9. doi: 10.1016/j.surg.2013.06.033

29. Erdogan I, Deutschbein T, Jurowich C, Kroiss M, Ronchi C, Quinkler M, et al. The role of surgery in the management of recurrent adrenocortical carcinoma. J Clini Endocrinol Metabol. (2013) 98:181-91. doi: 10.1210/jc.2012-2559

30. Pommier RF, Brennan MF. An eleven-year experience with adrenocortical carcinoma. Surgery. (1992) 112:963-70.

31. Zhang F, Liu Z, Liang J, Tang Y, Liu S, Zhou C, et al. Operative intervention for recurrence of adrenocortical carcinoma: A single-center experience. Surgery. (2020). doi: 10.1016/j.surg.2020.10.041

32. Terzolo M, Angeli A, Fassnacht M, Daffara F, Tauchmanova L, Conton PA, et al. Adjuvant mitotane treatment for adrenocortical carcinoma. N Engl J Med. (2007) 356:2372-80. doi: 10.1056/NEJMoa0 63360

33. Veytsman I, Nieman L, Fojo T. Management of endocrine manifestations and the use of mitotane as a chemotherapeutic agent for adrenocortical carcinoma. J Clin Oncol. (2009) 27:4619-29. doi: 10.1200/JCO.2008.17.2775

34. Lo W, Ayabe RI, Kariya CM, Good ML, Steinberg SM, Davis JL, et al. Stage and disease-free interval hel $p$ select patients for surgical management of locally recurrent and metastatic adrenocortical carcinoma. J Surg Oncol. (2019). doi: 10.1002/jso.25790

35. Zhang F, Zhang F, Liu Z, Wu K, Zhu Y, Lu Y. Prognostic role of $\mathrm{Ki}-67$ in adrenocortical carcinoma after primary resection: a retrospective mono-institutional study. Adv Ther. (2019) 36:2756-68. doi: 10.1007/s12325-019-01050-0

36. Beuschlein F, Weigel J, Saeger W, Kroiss M, Wild V, Daffara F, et al. Major prognostic role of Ki67 in localized adrenocortical carcinoma after complete resection. J Clin Endocrinol Metab. (2015) 100:8419. doi: 10.1210/jc.2014-3182

37. Wang F, Shu X, Meszoely I, Pal T, Mayer I, Yu Z, et al. Overall mortality after diagnosis of breast cancer in men vs women. JAMA oncology. (2019). doi: 10.1001/jamaoncol.2019.2803

Conflict of Interest: The authors declare that the research was conducted in the absence of any commercial or financial relationships that could be construed as a potential conflict of interest.

Publisher's Note: All claims expressed in this article are solely those of the authors and do not necessarily represent those of their affiliated organizations, or those of the publisher, the editors and the reviewers. Any product that may be evaluated in this article, or claim that may be made by its manufacturer, is not guaranteed or endorsed by the publisher.

Copyright (๑) 2022 Zhang, Liu, Feng, Tang, Liu, Wu, Zhang, Zhu and Lu. This is an open-access article distributed under the terms of the Creative Commons Attribution License (CC BY). The use, distribution or reproduction in other forums is permitted, provided the original author(s) and the copyright owner(s) are credited and that the original publication in this journal is cited, in accordance with accepted academic practice. No use, distribution or reproduction is permitted which does not comply with these terms. 